\title{
FINANÇAS PÚBLICAS VERDE NO BRASIL: UMA REVISÃO BIBLIOGRÁFICA
}

\section{BASIS FOR A GREEN FISCAL POLICY IN BRAZIL}

Recebido: 15.08 .2017

Aprovado: 23.10.2017

José Roberto R. Afonso*

RESUMO: O presente estudo tem por intuito complementar a literatura nacional acerca do tema economia verde e desenvolvimento sustentável, a partir de uma abordagem das finanças públicas e visando promover uma reflexão por parte dos analistas, autoridades e os responsáveis por formular e executar a políticas verde. Entende-se, aqui, que a necessidade de proteção ao meio ambiente também compreende o direito tributário e, a partir de normas eficientes às demandas ambientais, é possível promover maior desenvolvimento sustentável.

Palavras-chave: Finanças públicas. Economia verde. Direito Tributário.

ABSTRACT: The purpose of this study is to complement the national literature on the green economy and sustainable development, based on a public finance approach and to promote reflection on the part of analysts, authorities and those responsible for formulating and implementing green policies. It is understood here that the need to protect the environment also includes tax law and, from efficient norms to environmental demands, it is possible to promote greater sustainable development.

Keywords: Public finances. Green economy. Tax law.

\section{INTRODUÇÃO}

O Brasil, por sua dimensão continental e pela importância do meio ambiente em sua sociedade e economia, é um dos países mais influentes nas discussões mundiais em torno do desenvolvimento sustentável. O País assumiu metas e compromissos internacionais ambiciosos visando aperfeiçoar a sustentabilidade ambiental. Neste contexto, da economia verde ao desenvolvimento sustentável, cresceram estudos, avaliações e até recomendações de políticas específicas em diferentes enfoques. Mas em um deles, o das finanças públicas em geral, entende-se que ainda há muito por se refletir, pesquisar e decidir no País.

\footnotetext{
* Economista e contabilista, professor do curso de Mestrado de Direito Constitucional do Instituto Brasiliense de Direito Público (IDP) e pesquisador do Instituto Brasileiro de Economia da Fundação Getúlio Vargas (IBRE/FGV), e consultor de organismos internacionais. E-mail: < zeroberto@joserobertoafonso.com.br >.

Este artigo tomou por base esforço iniciado com pesquisa sobre o tema da política fiscal verde para a Comissão Econômica da América Latina - CEPAL.
} 
Tributos, subsídios, renúncias, gastos e mesmo intervenção pública em preços, são instrumentos que impactam o meio ambiente. Mas por maiores que sejam seus pesos e suas consequências, no Brasil aquelas ainda têm sido tratadas à parte, à margem, das questões ambientais. Como se fossem dois mundos paralelos, que não se misturam: cada um, com suas especificidades. É comum que defensores das causas ambientais (como também das sociais) reclamem da falta de recursos públicos suficientes para custear suas ações, como se fossem negados ou negligenciados pelos defensores dos cofres públicos e da economia. Da academia aos governos, é necessária uma abordagem de ambas questões por enfoque multidisciplinar para se equilibrar e dar mais eficácia as políticas públicas e as ações coletivas.

Objetivando dar uma contribuição nessa direção, de se lograr uma abordagem mais integrada das questões fiscais e ambientais no Brasil, este trabalho se propõe a fazer um esforço de levantar e revisar a bibliografia que tem tratado desses temas. A justificativa é traçar ao menos um diagnóstico mais circunstanciado e atualizado dos objetivos e dos efeitos, seja da política fiscal, em seu sentido mais amplo (compreendendo gastos, orçamento, contabilidade e finanças em geral do governo), seja da política tributária, com seu enfoque mais específico (na cobrança de impostos e contribuições). É preciso melhor se conhecer aonde se encontra antes de definir para onde se quer caminhar e traçar o rumo para lá se chegar. Esta é uma forma simplificada de definir um processo de planejamento estratégico, que o Brasil tanto tem carecido em termos mais genéricos e nacionais.

O esforço de reflexão a ser desenvolvido passará por: identificar, dentre outros elementos, os tributos mais diretamente afetos à problemática ambiental; e avaliar a eficácia da política fiscal, seja com o uso de instrumentos como o subsídio ou a renúncia tributária, seja mediante a administração do gasto público. O intuito é oferecer subsídios técnicos às autoridades e especialistas interessados em conhecer e utilizar a política fiscal como meio de induzir e alcançar o desenvolvimento sustentável.

A estrutura do trabalho compreende, inicialmente, uma breve contextualização das instituições e instrumentos vigentes no Brasil. A maior parte do trabalho é dedicada a levantar uma bibliografia a mais extensa possível e traçar uma resenha de seus principais temas e resultados.

A metodologia de trabalho se vale basicamente de uma pesquisa bibliográfica e exploratória, sempre que possível destacando evidências empíricas e quantitativas. A atenção inicial é para situar o contexto institucional no qual são formuladas e executadas as políticas públicas que envolvem as finanças públicas e o desenvolvimento sustentável. A partir daí se vale de uma metodologia qualitativa que procura levantar a bibliografia mais extensa possível, pesquisando obras nacionais, e também estrangeiras, com objetivo de elaborar uma resenha que permita identificar os traços mais característicos da tributação, no sentido mais restrito, e da fiscalidade, no sentido mais amplo, ambos preocupados ou repercutindo sobre o desenvolvimento sustentável brasileira recente. É um estudo descritivo muito mais baseado na busca de informações e opiniões na literatura do que na construção de dados em si. 


\section{CONTEXTUALIZAÇÃO INSTITUCIONAL}

É interessante, antes de tudo, situar brevemente questões e instituições que tratam e regulam o meio ambiente e o desenvolvimento sustentável no Brasil, com os fins de ajudar no trabalho seguinte de traçar uma resenha bibliográfica focada na sua interação com as finanças públicas em geral.

A agressiva exploração dos recursos naturais objetivando puramente o desenvolvimento econômico obviamente tem prejudicado o meio ambiente. Esse contexto há tempos preocupa a sociedade, pois a elevação da qualidade de vida da sociedade aliada ao crescimento econômico depende, inevitavelmente, do tratamento ambiental. Dessa forma, é fundamental a harmonização entre a preservação do ambiente e o desenvolvimento econômico, utilizando uma exploração racional dos recursos, a fim de garantir o bem-estar de presentes e futuras gerações.

A necessidade de uma proteção ao meio ambiente pode ser fruto do direito tributário, desde que as suas normas sejam eficientes às demandas ambientais e que possibilitem um desenvolvimento sustentável. Nesse contexto, é eminente e necessária uma relação entre o Sistema Tributário Nacional e a política nacional voltada ao meio ambiente, a fim de obedecer e cumprir os termos presentes na Constituição brasileira.

Vale destacar que a Constituição de 1988, além de abordar a preservação do meio ambiente, especialmente no capítulo XVI, no qual o art. 225 possui um papel de guia na condução de uma política que abrange um direito de todos ao meio ambiente ecologicamente equilibrado, também define as competências privativas da União, as concorrentes, as comuns e as dos municípios, respectivamente nos artigos 22, 24, 23 e 30. Tal iniciativa tem como objetivo promover a descentralização da proteção ambiental, permitindo uma ampla competência aos entes para legislarem sobre o meio ambiente.

Entre os princípios gerais das atividades econômicas da Constituição, no caso do art.17o, inciso VI, é mencionado que a ordem econômica tem por fim assegurar a todos existência digna da defesa do meio ambiente, inclusive mediante o tratamento diferenciado conforme o impacto ambiental dos produtos e serviços e de seus processos de elaboração e prestação.

Há uma legislação específica para o setor ambiental que acaba criando uma das principais fontes de financiamento dos correspondentes órgãos governamentais. Dessa forma, destaca-se a Lei de Crimes Ambientais, n. 9.605, de 12/02/1998, a qual dispõe sobre as sanções penais e administrativas derivadas de condutas e atividades lesivas ao meio ambiente, e dá outras providências.

No título do sistema tributário, previsto na Constituição da República vigente, foram classificadas como Contribuições, de competências exclusivas da União, aquelas que possuem uma vinculação direta ao financiamento da questão e preservação ambiental, embora seu comando específico esteja em outros títulos constitucionais. No título da ordem econômica, posteriormente à Assembleia Constituinte de 1987/1988, foi criada e regulada a contribuição para intervenção no domínio econômico incidente sobre combustíveis. Já no título da organização do Estado, foi previsto que a exploração de recursos naturais, tais como petróleo, inclusive no mar territorial, energia elétrica 
e minerais, geraria compensações e indenizações aos governos dos territórios em que foram extraídos. A cobrança foi regulada por legislação posterior.

A Lei no 10.336 , de 19/12/2001, instituiu a Contribuição de Intervenção no Domínio Econômico (CIDE) incidente sobre a importação e a comercialização de petróleo e seus derivados, gás natural e seus derivados, e álcool etílico combustível, que tem como um de seus objetivos o financiamento de projetos ambientais relacionados com a indústria do petróleo e do gás.

A cobrança de royalties e participações especiais sobre a extração de petróleo e gás, inclusive no mar territorial, é que gera mais receitas e também passou a despertar conflitos federativos sobre a divisão de sua receita. Segundo a atual legislação brasileira, estados e municípios produtores têm direito à maioria dos repasses. A divisão atual é de 40\% da União, 22,5\% para os estados e 30\% para os municípios, sendo que os restantes $7,5 \%$ são distribuídos para todos os municípios e estados da federação.

No campo específico dos impostos, adianta-se que não há mais um específico sobre recursos naturais e nem um com receita a ser aplicada diretamente vinculada à causa ambiental.

Mencionam-se inicialmente os impostos sobre produção e vendas. O imposto sobre produtos industrializados - IPI, de competência da União, poderá apresentar alíquotas seletivas em razão da essencialidade ambiental ou do porcentual de matériaprima reciclada utilizada na fabricação dos produtos. O imposto sobre circulação de mercadorias e prestação de serviços de comunicações e transportes - ICMS, imposto de competência dos estados, é que desperta mais atenção porque em algumas unidades federadas o repasse da cota-parte para municípios passou a considerar o cumprimento de determinadas metas de proteção ambiental. No caso do imposto sobre serviços de qualquer natureza - ISS, imposto de competência dos municípios, os incentivos se darão às empresas que invistam em questões ambientais, além da redução ou isenção do imposto a determinados serviços como ecoturismo.

Entre os impostos patrimoniais, a questão ambiental aparece mais vinculada às renúncias. Há isenção para áreas de preservação permanente no caso do imposto sobre propriedades territoriais rurais, competência da União. Também no caso do imposto sobre propriedade predial e territorial urbana - IPTU, competência municipal, propriedades que não respeitarem o meio ambiente serão submetidas ao IPTU progressivo. Já no caso do imposto sobre propriedade de veículos automotivos - IPVA, imposto de competência dos estados, há uma redução das alíquotas ou isenção para determinados veículos que utilizam energia limpa ou combustíveis menos poluentes.

Já sobre a renda, no caso do imposto de renda - IR, o qual possui competência da União, haverá incentivos às pessoas físicas ou jurídicas que financiem projetos que visam à proteção ambiental ou que doem.

É possível antecipar que algumas políticas ocorridas nos últimos anos se contrapõem ao projeto de gestão ambiental, aumentando ainda mais incentivos à indústria mais poluente do meio ambiente como, por exemplo, a produção deautomóveis, beneficiada pela guerra entre os estados do imposto ICMS. 
Outra política está associada à redução de impostos federais no período pós-crise (especialmente IPI), sob o pretexto de estimular a economia. Além disso, houve uma redução e isenção total da contribuição de intervenção no domínio econômico incidente sobre combustíveis - CIDE (imposto com função reguladora) para compensar as perdas de refinarias enquanto se congelava o preço da gasolina, o que não conseguiu impedir o aumento da inflação no país e acarretou sérios danos às finanças da maior empresa do país, crise no setor de etanol (dívida e falência de usina de etanol) e continuação da descida das receitas fiscais de combustíveis.

A nota deste autor "Tributação versus subsídios: o caso da Petrobras" trata, de forma geral, da relação desta empresa estatal com o sistema tributário, uma vez que aborda a evolução e a estrutura dos recolhimentos pela estatal de impostos, contribuições e participações, com base nos dados que divulga aos investidores e ao controle do governo central de empresas estatais - ver (AFONSO, 2014b).

Para a compreensão geral do sistema tributário brasileiro é referenciado Afonso, Morais e Castro (2012), assim como Távora et.al.(2015) e TCM-SP (2011).

Voltando à institucionalidade de políticas nacionais ambientais, importa lembrar o acordo estabelecido entre 195 países durante a Conferência do Clima (COP21), em Paris, onde países ricos não só se comprometeram a financiar um fundo anual para a redução do aquecimento global, como também se propuseram a contribuir para a geração de uma economia com menores índices de uso de carbono e energias fósseis, estabelecendo para tais países o desafio de nos próximos cinco anos repensar suas políticas em prol de economias que consigam conciliar o desenvolvimento com a pauta verde.

Também muito importante no ano de 2015 foi a determinação, na cúpula de chefes de Estado e de governo que antecedeu a $70^{\mathrm{a}}$ Assembleia Geral da Organização das Nações Unidas - ONU, dos 17 Objetivos de Desenvolvimento Sustentável (ODS) que orientam a agenda global até 2030, em substituição aos Objetivos de Desenvolvimento do Milênio (ODM). Detalhados em 169 metas, os ODS passam a contemplar um amplo conjunto de questões ambientais, como manejo da água, energia, resiliência, padrões de consumo e produção sustentáveis, combate à mudança do clima, uso dos oceanos e florestas, entre outros temas.

\section{RESENHA BIBLIOGRÁFICA}

Um levantamento da literatura de finanças públicas para o desenvolvimento sustentável, com particular atenção para a tributação, conclui por um estágio muito diferenciado entrea produção intelectual internacional, com produção farta, diversificada e crescente, e a mesma produção nacional, que pode ser considerada rara e rasa, ao menos quando se busca a interação entre os dois temas pesquisados.

\subsection{Literatura Estrangeira}

Da literatura estrangeira dedicada ao tema, vale destacar alguns títulos que podem servir de paradigma e também complementar a análise da experiência brasileira: 
Green Fiscal Commission (2009-2010); Heine et.al. (2012); Helfand (1999); IEA (2013); IEA (2014); IMF (2010); KPMG (2013); OCDE/CEPAL/CIAT (2014); Olive e Héctor (2010); ONU (2012); OECD (2011); Parry (2012); Pigou (1920); Pollitt (2015); e Salmons (2011), dentre outros autores. É importante ressaltar que nenhum desses autores tratou especifica e exclusivamente do caso brasileiro.

Alguns casos mercerem mais atenção. Em estudo recente a respeito da reforma fiscal ambiental (RFA) na América Latina, a CEPAL, Fanelli et.al. (2015) aponta o fato de que tal reforma possui baixa prioridade nas agendas políticas de alguns países por questões que se distinguem de região para região, como a composição e importância das fontes de emissão de $\mathrm{CO}^{2}$ e a significativa presença de subsídios à energia. Neste mesmo estudo, destaca-se a distribuição altamente concentrada das emissões no bloco. Apenas seis países respondem por $85 \%$ das emissões, enquanto Brasil e México são responsáveis sozinhos por $60 \%$.

Importante comentar sobre a motivação extrafiscal de tributos ambientais, ou seja, não objetivar necessariamente o aumento da arrecadação. O que se pretende é estabelecer incentivos e desincentivos para que a produção de bens e serviços seja sustentável, como explorado, por exemplo, em: Nery (2014); Pigou (1920); e Helfand (1999).

Uma menção à parte é válida para o Fundo Monetário Internacional - FMI, cujo departamento fiscal (FAD) passou a dedicar atenção crescente ao tema específico do chamado low carbon tax, com reflexões conceituais - ver, por exemplo, Parry (200o e 2014)-e reproduzindo a experiência já adotada em vários países. ${ }^{1}$

Partindo do acordo firmado em Paris e já mencionado, estudo publicado pelo FMI- ver Coady et.al. (2015) - apresenta um balanço das implicações de grande alcance impostas pelas mudanças climáticas para as políticas macroeconômicas, apontando a necessidade primária de se reconhecer e explorar o potencial papel das políticas fiscais na implementação dos compromissos de mitigação apresentados na Conferência. É destacado que no coração da mudança climática encontra-se uma externalidade - o fato de empresas e famílias não serem cobradas pelas consequências ambientais de sua própria emissão. Isto fundamenta o papel central do estabelecimento de uma taxa adequada sobre as emissões, o que significa em outras palavras a remoção de um subsídio implícito no fracasso da cobrança de custos ambientais.

O estudocitado do FMI acentua a importância de políticas fiscais na mobilização de forma eficiente de recursos públicos e privados, enquanto a necessidade de adaptar as economias às mudanças climáticas levanta questões que têm implicações para o desenho dos sistemas de gastos e impostos nacionais. Localizando no centro da missão de reduzir as emissões o processo de precificação do carbono, os autores reconhecem que o caminho para o preço adequado e a forma de lidar com os efeitos adversos sobre empresas e famílias vulneráveis, assim como as consequentes sensibilidades políticas, são os maiores desafios que se instauram. Na medida em que esquemas de precificação nacional emergem, uma forma natural de aumentar

1 Vale ver também o seguinte blog especializado no tema: http://www.carbontax.org/blog/ . 
tais esforços e a preocupação em termos de perda de competitividade seria através de arranjos em prol de um preço mínimo internacional para o carbono - análogos àqueles desenvolvidos para combater alguns casos de competição internacional sobre bases tributárias móveis.

Ampliando a abrangência da análise, passando dos tributos para a política fiscal, em seu sentido mais amplo, contemplando também gastos públicos e outros aspectos, é possível destacar o levantamento de alguns trabalhos mais focados na América Latina, no qual o Brasil acaba sendo examinado ou dele pode extrair, a saber: PNUMA (2014); Acquatella e Bárcena (2005); IPAM (2014); Sabaíni e Morán (2013, 2014).

Ainda que não seja diretamente uma matéria própria das finanças públicas, e sim trate das finanças privadas, existem estudos em que muito se respeita àquelas matérias. Coady et.al. (2015) ressaltam a crescente necessidade do setor financeiro assumir nível de contribuição (seja facilitando investimentos limpos ou repartindo riscos relacionados ao clima) e de fortalecer as supervisões regulatórias dos países, com o objetivo de alcançar mercados financeiros e instituições mais sólidas e resistentes que possam ter em mãos instrumentos para gerir riscos climáticos.

Ainda nesse tema, mas optando por outro foco, há quem tenha se dedicado a analisar um possível futuro verde com base em medidas que não se limitem à política tributária, mas envolvam também a melhoria de geração de energia ao redor do mundo com apoio do setor público- o que contraria o senso-comum, segundo Mazzucato (2016). Para a autora, apesar de essa constatação soar surpreendente, uma vez que a maior parte das inovações na economia é associada ao setor privado como fonte de recursos, algumas iniciativas públicas já superam os gastos dos famosos bilionários da tecnologia. Exemplos dados são os programas Arpa-E (EUA), Yozma (Israel) e Sitra (Finlândia), casos onde o governo retém participações nas inovações financiadas pelo Estado, permitindo que este assuma uma posição empreendedora e continue a investir, estimulando a próxima onda de inovações.

O prêmio Nobel James Buchanan, em trabalho de 1975, demonstra que as normas podem causar menor aumento de custo para os poluidores do que os tributos, motivo pelo qual eles teriam maior resistência aos impostos ambientais, o que os torna um problema político Nery (2014). Entre os seguidores e apoiadores estão Miller e Vela (2013); Dietz e Vollebergh (1999); Buchanan (1975).

Um último comentário respeita as citações predominantes ao Brasil em meio a essa literatura internacional aqui levantada. A menção não é motivo para maiores comemorações, mas sim preocupações. O Brasil merece (triste) destaque como um dos países em que a contribuição da gasolina como combustível emissor de $\mathrm{CO}^{2}$ é mais elevada e ainda representa uma relação com taxas em excesso não ligadas a emissão de poluente, fato este que difere de outros países que seguem a tendência de taxar o carbono diretamente - (PARRY, 2014, 2012); (GREEN FISCAL COMMISSION, 2010); (IPAM, 2013), (IMF, 2015). 


\subsection{Literatura Nacional}

A produção brasileira que trata de questões tributárias, fiscais e ambientais, simultaneamente, é muito mais limitada e algo recente.

A política tributária acaba despertando mais atenção. Dentre raros trabalhos que tem por objeto tratar dos seus impactos ambientais, é o caso de Appy et.al. (2014). Ele se debruçou sobre a legislação tributária brasileira na tentativa de encontrar caminhos para a taxação de atividades poluentes, porém sem que se somassem novos tributos à nossa já pesada carga tributária. A proposta dessa pesquisa foi encomendada a esse economista pelo Instituto de Pesquisa Ambiental da Amazônia (IPAM, 2014) e Instituto Ethos e apresentada ao Senado, em um seminário (SPE, 2014). Na conclusão de suas reflexões, Appy apresentou a ideia da CIDE-Carbono, uma nova versão da Contribuição de Intervenção no Domínio Econômico (CIDE), que incidiria, em um primeiro momento, sobre os combustíveis fósseis e a pecuária de baixa produtividade, dois dos grandes responsáveis pelas emissões de gases de efeito estufa no Brasil. (ASTORGA, 2015); (DOMINGUES, 2015); e (BRITO, 2015).

A contribuição de Appy (2015), no estudo de práticas que contribuiriam para o futuro sustentávelambiental do Brasil, refere-se principalmenteà necessidadedesafiadora de criar mecanismos que promovam a substituição de fontes de energia intensivas em gases do efeito estufa por outras fontes que sejam mais limpas e, ao mesmo tempo, não danifiquem ainda mais a economia do país. Como ponto de partida, o autor analisou as dificuldades relacionadas ao cumprimento das metas de emissão estabelecidas pelo "Intended Nationally Determined Contribution Towards Achieving The Objective Of The United Nations Framework Convention On Climate Change" (INDC-Brasil, 2015) que, quando comparadas às emissões totais de $\mathrm{CO}^{2}$ em 2005, representariam uma queda de $37 \%$ nas emissões totais para 2025 e de $43 \%$ para 2030. Diante dessas considerações, o autor destacou a questão da taxação do carbono (carbon tax) e os possíveis cenários e consequências diante do objetivo final de examinar os impactos econômicos, ambientais e sociais de uma alteração no sistema tributário brasileiro.

Levantando estudos e documentos dentre os divulgados pelo governo brasileiro, um caso raro e específico a tratar das questões aqui pesquisadas foi de evento realizado há poucos anos. Proposto pela Secretaria de Política Econômica do Ministério da Fazenda, com apoio da Embaixada do Reino Unido e executado pela GVces, o Seminário Política Fiscal Verde no Brasil traçou um panorama completo a respeito dos instrumentos de política fiscal em uso no Brasil que possuem potencial para promover uma economia verde - vide seus trabalhos e conclusões em (SPE, 2015); (FGV, 2013).

Atentando que o Brasil é uma federação e descentralizada, de direito e de fato, ainda há atenção aos governos regionais. Muitos deles vêm investindo em experiências de fomentar a proteção ambiental utilizando impostos já existentes, como IPTU, IPVA e ICMS. O chamado ICMS ecológico, ou verde, vem sendo utilizado por vários estados que passaram a legislar agregando um critério ambiental de redistribuição da parcela do imposto, que é estadual, aos municípios. (OLIVEIRA e ALMEIDA, 2015) 
Mudando o foco da tributação para do gasto público, sempre vinculado à proteção e ao desenvolvimento ambiental, a literatura nacional se torna ainda mais rara. Levantamento encontrou estudos de Young et.al., (2007, 2011, 2012); Diniz e Afonso (2013); Bremaeker (2013).

Cabe ainda tratar dos preços administrados pelos Estados. Esteé um elemento que não envolve tributo ou gasto público, porém, pela peculiaridade institucional brasileira tem um peso e um efeito tão grande ou até maior do que aqueles instrumentos fiscais clássicos.

O impacto da intervenção discricionária do governo na política de precificação impõe pressão importa sobre a economia brasileira. A discussão sobre os impactos nefastos nas empresas - como no caso de Oliveira e Almeida (2014); Branco (2014); e Losekann e Haydt (2013). Já o impacto de impostos verdes influencia as atividades ligadas à extração de recursos naturais como o petróleo é discutida por Amorin (2011); Afonso (2014); e Oliveira e Almeida (2014).

\section{POLÍTICA VERDE OU VERMELHA?}

É interessante apresentar à parte uma reflexão crítica sobre um aspecto particular da experiência brasileira em que a implementação de instrumentos da política econômica produziu um efeito exatamente inverso ao esperado em termos de desenvolvimento sustentável. Uma forma de exemplificar tais reflexões é comentar a tributação de combustíveis no País até 2014. É um caso exemplar para mostrar como se prometia uma política, mas se praticava outra, na direção completamente oposta e para propor medidas corretivas que mirem o longo prazo e dissemine impactos positivos na economia.

À custa das maiores renúncias tributárias conhecidas, da desoneração do IPI à guerra fiscal do ICMS estadual, se reduziu, continua e fortemente, a carga sobre a venda de automóveis (mas não sobre os transportes de massa) e, pior, sobre combustíveis fósseis (caso dos derivados de petróleo). E, neste último caso, nenhum outro país do mundo dispunha do etanol, produzido em escala continental, como uma alternativa muito mais viável para produção, emprego e renda, e ainda interessante para o meio ambiente e a saúde.

Essa combinação perfeita foi arrasada pela política oportunista de administrar, como já confessado por Ministro de Estado, os preços da gasolina e do diesel para tentar frear a inflação. Fez isso sem separar dotação no orçamento para cobrir os correspondentes subsídios. Estes, na prática, foram transformados em redução de tributos sobre aqueles bens e, depois, em prejuízos bilionários, e já mensurados, para Petrobras, de modo que o governo perdeu receita e também patrimônio. Esse caminho tortuoso jogou na crise importantes setores da economia - do agronegócio à construção pesada - e tornou inglório repetir o ajuste fiscal feito tantas vezes no passado, porque nunca foi tão deprimida a arrecadação proveniente desse setor estratégico.

Os números evidenciam como se espalhou o vermelho nas contas públicas e nacionais. A contribuição específica - a CIDE (criada pela Lei 10.336/2001) representava 
$14 \%$ do preço na bomba da gasolina em 2002, contra atuais $2.2 \%$, mesmo depois do reajuste do início do ano - se fosse mantida aquela proporção, a alíquota deveria subir de o,10 para o,62 centavos por litro. Já o PIS/COFINS, também cobrado como um valor fixo por litro vendido, ficou congelado (em R $\$ 0,2616$ ) por quase dez anos (só reajustado pelo Decreto 8395/2015). Somados esses três tributos, a PETROBRAS deveu R\$ 16,2 bilhões em 2014 contra $\mathrm{R} \$ 29,8$ bilhões em 2006 - tal perda de receita equivale, por exemplo, a um ano do gasto com atenção básica à saúde no orçamento federal. Outro valor, equivalente, deve ser perdido com royalties sobre petróleo, em que o efetivamente arrecadado tem caído muito mais que os preços internacionais e apesar da produção agora em alta. A carga tributária total da Petrobras caiu para o piso de 1,71\% do PIB neste primeiro trimestre, o,6 ponto abaixo do mesmo há quatro anos. Nem é preciso dizer quanto faz falta tal receita oriunda de petróleo e derivados para o ajuste fiscal.

Outros números mostram como o vermelho também se espalhou para a produção na economia e para própria saúde humana. Já foram fechadas 70 usinas, e 30 estão em recuperação judicial, com perda de 60 mil empregos diretos. A venda de máquinas para o setor caiu pela metade. Mesmo assim, estudos projetam que, depois do carro flex, se reduziu a emissão de gases estufa em 250 milhões/t de $\mathrm{CO}_{2}$ e se evitaram 9 mil internações por problemas respiratórios e cardíacos.

Enfim, ao menos até 2014, vermelho foi a cor que, no Brasil, virou a política que deveria seria verde, para enfrentar as mudanças climáticas, e que, na tributação, deveria punir o que mais polui e premiar a energia limpa. Por mais que o país tenha aderido a pactos internacionais nessa direção, foi exatamente o oposto que fez ao adotar medidas impostas até 2014 por forças das circunstâncias, sem planejamento estratégico, pois pareciam as mais fáceis, nem que fosse para postergar os problemas.

Se algo útil houve na crise, econômica e fiscal, foi abrir ao menos a oportunidade ímpar para se promover mudanças que, além do ajuste, promovam uma consolidação. Foi recomendado e se promoveu a recuperação paulatina, entre 2015 e 2017, da antiga proporção de tributos sobre derivados de petróleo que já tiveram a CIDE mais o PIS/ COFINS (somadas já tinham alcançado $23,2 \%$ do preço de bomba da gasolina $\mathrm{C}$ ). Mais importante é que, depois, tais contribuição passaram a ser reajustadas automaticamente com os preços de revenda.

O maior espaço futuro para aumento de arrecadação federal deve estar na taxação dos lucros do setor de petróleo, que se espera venham a ser recuperados junto com as finanças da empresa estatal que domina o setor. Também os royalties e participações na extração poderiam passar a ser cobrados e/ou fiscalizados pela Receita Federal (afinal esta não é uma taxa para custeio de agência reguladora, como no caso das demais cobranças por elas realizadas). O cálculo da participação especial deveria ser reestruturado (basta Decreto presidencial) para atender ao princípio legal de alcançar a rentabilidade dos campos - qualquer produção deveria ser alcançada, sem isenção, e introduzida uma fórmula que funcione como curva e não escada. No próprio ICMS, poderiam ser pactuadas uma revisão e a redução gradual dos incentivos para produção e consumo de fontes poluidoras (como combustíveis e como veículos) em troca de uma 
nacionalização das menores alíquotas já praticadas por alguns estados no caso de fontes limpas (como etanol).

Enfim, há uma enorme oportunidade aberta pela crise para o Brasil atender às metas mundiais com o meio ambiente e, ao mesmo tempo, recuperar receitas, consolidar o ajuste fiscal, estimular a agroindústria nacional e ainda gastar menos com saúde. Neste campo, há de se avançar rumo ao passado na tributação de combustíveis, que conciliava disciplina e crescimento, mas foi desperdiçado em troca da inflação, da qual não se escapou e só se adiou a conta para hoje. É hora de trocar o negro do buraco das contas públicas e o vermelho das finanças dos setores de energia pelo verde, como novo norte para a política tributária e fiscal e também para nova e melhor economia.

\section{OBSERVAÇÕES FINAIS}

Este artigo mostrou que as relações entre finanças públicas e meio ambiente no Brasil pouco foram abordadas em conjunto na literatura nacional. A internacional até dedica um espaço para a experiência brasileira que pode ser considerado relevante ou as vezes mais extensa que a nacional. Essa carência de estudos é ainda maior se focado nos temas dos gastos públicos do que nos aspectos específicos da tributação.

A ótica da proteção ao meio ambiente e ao desenvolvimento sustentável não tem merecido muita atenção dos fiscalistas e tributaristas, nem dos analistas, muito menos das autoridades fazendárias e mesmo dos parlamentares, que formulam e executam a política tributária nacional.

Essa falta de atenção ou compromisso compromete a eficácia da política fiscal quando utilizada como instrumento de promoção do desenvolvimento sustentável. Não raro, medidas que tendem a estimular o uso de energia menos agressiva ao meio ambiente através da concessão de benefícios tributários acabam neutralizadas ou mesmo compensadas por efeitos na direção oposta decorrentes de outras medidas, inclusive incentivos fiscais, que, mirando em outros objetivos (como o combate à inflação), acabam favorecendo consumo do que é mais danoso ao meio ambiente è̀ saúde.

É inegável que políticas no campo das finanças públicas não foram eficientes e eficazes para a condução de um desenvolvimento sustentado em proteção ao meio ambiente. Tal constatação vai além de discutir que as dotações orçamentárias destinadas especificamente para a área ambiental ainda são insignificantes se comparadas ao potencial econômico das atividades envolvidas.

O Brasil continua a ser uma experiência do que deve e não deve ser feito. Embora muito já se tenha estudado sobre como se cobram tributos no País, inclusive como se exigem royalties e participações da extração de recursos naturais, e recentemente também se tenha passado a pesquisa mais sobre a evolução e a estrutura do gasto público, ainda pouca atenção se dá ao meio ambiente em termos de objetivos e impactos de políticas. O levantamento e a resenha bibliográfica aqui apresentados apontam que o desenvolvimento sustentável merece no País pouca preocupação ou atenção na formulação e execução da política tributária, no sentido restrito, e da política fiscal, incluindo gastos e outros aspectos, passando pela arbitragem de preços administrados. 


\section{REFERÊNCIAS}

AFONSO, José Roberto. Ingresos fiscales, recursos naturales e impuestos verdes: Comentarios de BRASIL. In: XXVII Seminario regional de política fiscal. (CEPAL), 2014, Santiago. Apresentação em Power Point. Disponível em: < http://bit.ly/1gOdved >. jun. 2014.

Tributação versus Subsídios: o caso da Petrobrás. Nota Técnica IBRE/FGV. Rio de Janeiro, junho 2014. Disponível em: < http://bit.ly/1kL76Ea >. Acesso em: jun. 2014.

; SOARES, Julia Morais; CASTRO, Kleber Pacheco de. Avaliação atualizada da estrutura e do desempenho do sistema tributário brasileiro: Livro branco da tributação brasileira.

AMORIN, Livia Medeiros. Histórico da Tributação do Setor de Petróleo e Gás: da Primeira República aos tempos atuais. Considerações sobre arranjos federativos das receitas tributárias do setor. 2011. TCC (Graduação). Curso de Direito, Universidade de Brasília, Brasília, 2011.

APPY, Bernardo. Taxação sobre carbono, competitividade e correção de distorções do sistema tributário: Impactos na economia brasileira. São Paulo: Instituto Escolhas , 2015.

. et al.; . Cide-Carbono: mais florestas, menos gases estufas. In: LIMA, André.; MOUTINHO, Paulo. (Orgs.). Política Tributária Brasileira e sua "Pegada" Climática: por uma transição rumoà sustentabilidade. Brasília: Instituto de Pesquisa Ambiental da Amazônia, 2014. Disponível em: < http://bit.ly/1KdGOJv >. Acesso em: jul. 2014.

ASTORGA, Isabel Rojas. Impuesto a contaminantes locales y CO2 em Chile. Chile, 2015. Ministerio Del Medio Ambiente. Gobierno de Chile.

BREMAEKER, François E. J. As Despesas Municipais com a Função Gestão Ambiental em 2011. Associação transparência municipal ATM-TEC, Salvador, n. 253, ago. 2013. Estudo Técnico. Disponível em:< http://bit.ly/ijtkQTV > Acesso em: jul. 2014.

BRITO, Matheus Alves de. Experiências internacionais com tributos sobre carbono. In: WAYCARBON, 2015. Brasília Apresentação em Power Point. Brasília: Waycarbon, 2015, p. 1-42.

BRANCO, Vinicius. Tributação e sustentabilidade. Folha de São Paulo, São Paulo, jun. 2014. 
BUCHANAN, James; TULLOCK, Gordon. Polluters' Profits and Political Response: Direct Controls versus taxes. The American economic review, v. 65, 1975, p. 139-47.

COADY, David et al.; How large are global energy subsidies? IMF, may 2015. Disponível em: <http://bit.ly/1HUuOYr> Acesso em: jul. 2014.

COMISIÓN ECONÓMICA PARA AMÉRICA LATINA Y EL CARIBE, 2005, Santiago. Política fiscal y medio ambiente: Bases para una agenda común. Santiago: Jean Acquatella Alicia Bárcena, 2005. Disponible em: < http://bit.ly/1dEvMdY > Acesso em: jun. 2014.

DIETZ, Frank J.; VOLLEBERGH, Herman R.J., 1999. Explaining instrument choice in environmental policies. In: VAN DEN BERGH, J. (Org.). Handbook of environmental and resource economics. Northampton: Edward Elgar, 1999. p.339-351.

DINIZ, Érica; AFONSO, José Roberto. Benefícios Fiscais Concedidos (e Mensurados) pelo Governo Federal. FGV/IBRE, dez 2013. Texto para discussão, versão resumida publicada no Boletim MACRO IBRE. Disponível em:<http://bit.ly/1gwObdh $>$.

Benefícios fiscais concedidos (e Mensurados) pelo Governo Federal. In: FGV/ IBRE, fev. 2014, Rio de Janeiro. Apresentação em Power Point. Rio de Janeiro: FGV/ IBRE.

DOMINGUES, Prof. Dr. Edson. Simulação da tributação de carbono no modelo BeGreen. In: SEMINÁRIO POLÍTICA FISCAL VERDE, mar. 2015, Brasília.

FANELLI, José Maria; JIMÉNEZ, Juan Pablo; AZCÚNAGA, Isabel López. La reforma fiscal ambiental em América Latina. In: Comisión económica para América Latina Y El Caribe (CEPAL), dic. 2015 Documento de proyecto, U.N. Disponível em: < http://bit. ly/1Nxng4e >. Acesso em: ago. 2014.

FUNDAÇÃO GETULIO VARGAS. Política Fiscal Verde no Brasil. Rio de Janeiro: Centro de Estudos de Sustentabilidade da Fundação Getulio Vargas (GVces), fev. 2013.

GREEN FISCAL COMMISSION, 2009, UK. The Case for Green Fiscal Reform: Final Report of the UK Green Fiscal Commission. UK: Green Fiscal Commission, Oct. 2009. Disponível em: < http//www.greenfiscalcommission.org.uk > Acesso em: jul. 2014.

2010a, UK. reducing carbon emissions through transport taxation. UK: Green Fiscal Commission, Mar. 2010. Green Fiscal Commission. Briefing, Paper Six. Disponível em: < http//www.greenfiscalcommission.org.uk > Acesso em: jun. 2014. 
2010b. Competitiveness and Environmental Tax Reform. UK: Green Fiscal Commission, Mar. 2010. Green Fiscal Commission. Briefing, Paper Seven. Disponível em: $<$ http//www.greenfiscalcommission.org.uk >. Acesso em: jun. 2014.

HEINE, Dirk; NORREGAARD, John; Parry, Ian W.H.. Environmental Tax Reform: Principles from Theory and Practice to Date. In: INTERNATIONAL MONETARY FUND (IMF), Jul. 2012. Working Paper, 12/180. Disponível em: < http://bit.ly/1TOfhm4 > Acesso em: jul. 2014.

HELFAND, Gloria. Standards versus Taxes in Pollution Control. In: Van Den Bergh, J. (Org.). Handbook of environmental and resource economics. Northampton: Edward Elgar, 1999. p.223-234.

INTERNATIONAL ENERGY AGENCY, 2014, Paris. World energy outlook 2013: Executive summary., Paris: International Energy Agency, 2013..Disponível em: < http// www.iea.org >. Acesso em: jun. 2014.

. World Energy Outlook 2013. In: International Energy Agency, Jan.2014, Astana. Power Point Presentation.

INSTITUTO DE PESQUISA AMBIENTAL DA AMAZÔNIA. Pegada de carbono dos gastos tributários. Instituto de Pesquisa Ambiental da Amazônia, Out. 2013.

Política Tributária Brasileira e sua "Pegada” Climática: por uma transição rumo à sustentabilidade. Instituto de Pesquisa Ambiental da Amazônia, Dez. 2014.

KPMG. The KPMG Green Tax Index 2013: An exploration of green tax incentives and penalties. KPMG, 2013.

LOSEKANN, Luciano; Haydt, Gustavo. Mercado de combustíveis automotivos: Projeção de importações de gasolina, impactos econômicos e emissões de $\mathrm{CO}^{2}$. Rio de Janeiro: Instituto de Economia, Universidade Federal do Rio de Janeiro, mai. 2013. p. 18.

MAZZUCATO, Mariana. Revolução verde puxada pelo Estado. Valor Econômico, mar. 2016.

MILLER, Sebastian; VELA, Mauricio. Are Environmental Taxes Affected by Legislatures' Ideological Positions? Inter-American Development Bank. IDB,Sep. 2013.

NERY, Pedro Fernando. Como nossos impostos afetam o meio ambiente? Brasil, 2014. Economia e Governo. Disponível em: < http://bit.ly/1vopPTo >. Acesso em: 19 dez. 2014. 
OCDE/CEPAL/CIAT 2014, Santiago. Estadísticas tributarias en América Latina, 2014, Santiago. Santiago: OECD, 2014. Disponível em: < http://bit.ly/1bYpHbe > Acesso em: dez. 2014 .

OLIVE, Ferré; HÉCTOR, Edgardo. Hacia una Fiscalidad Ambiental: Centro Interamericano de Administraciones Tributarias (CIAT). Revista de Administración Tributaria CIAT/AEAT/IEF, n. 30, Dic. 2010. Disponível em: < http://bit.ly/1gOfosY > . Acesso em: jul. 2014.

OLIVEIRA, Patricia; ALMEIDA, Edmar de. Impactos da política de preços dos combustíveis sobre a Petrobras. .Infopetro, mai. 2015. Disponível em:< https://goo. gl/8XulvI >. Acesso em: set. 2014 .

. Impactos da política de controle indireto dos preços de gasolina, diesel e GLP na Petrobras. In: rio Oil \& Gas; expo and conference, 2014. Rio de Janeiro. Apresentação em Power Point. Rio de Janeiro: Rio Oil \& Gas; expo and conference, 2014.

Impactos econômicos da contenção dos preços de combustíveis no Brasil e opções para a política de preços. .Rio de Janeiro: Instituto de economia, Universidade Federal do Rio de Janeiro. set. 2014.

ONU. El Futuro Que Queremos. Resolución aprobada por La Asamblea General el 27 de julio de 2012. In: ONU.ASAMBLEA GENERAL, septiembre de 2012.Distr. General,. Disponible en: < http://bit.ly/1bGbJgs > Acesso em: ago. 2014.

ORGANISATION FOR ECONOMIC CO-OPERATION AND DEVELOPMENT (OECD) (2011). Taxation, Innovation and the Environment: A Policy Brief. In: OECD, Sept. 2011. Disponível em:< http://bit.ly/2cXjqQL > Acesso em: set. 2014.

PARRY, Ian W.H.. Environmental Taxes .In: INTERNATIONAL MONETARY FUND (IMF), UNEP/IMF/GIZ CONFERENCE., Oct. 2012, Geneva. Power Point Presentation. Geneva: IMF. Disponível em: < http://bit.ly/1bfhroX > Acesso em: out. 2014.

How much carbon pricing is in countries' own interests? The critical role of co-benefits. In: INTERNATIONAL MONETARY FUND (IMF), 2014. Disponível em:< http://goo.gl/8ABkoz > Acesso em: out. 2014.

Carbon pricing: Good for you, good for the planet' own interests? The critical role of co-benefits. In: International Monetary Fund (IMF), 2014. Disponível em: < http://goo.gl/A572Tp > Acesso em: out. 2014. 
; ANTONIO, M. Bento. Tax Deductions, Environmental Policy, and the "Double Dividend" Hypothesis. .Journal of environmental economics and management, 39, p. 67-96, 2000.

PIGOU, Arthur. The economics of welfare. Londres: Macmillan and Co, 1920.

PROGRAMA DAS NAÇÕES UNIDAS PARA O MEIO AMBIENTE. Reformas de la política fiscal para conseguir una economía verde. PNUMA: Economía Verde. Política Fiscal, 2014. Documento Informativo.

POLLITT, Hector. The E3-Brazil Model. In: GREEN FISCAL POLICY WORKSHOP CAMBRIDGE ECONOMETRICS, Mar. 2015, Brasilia. Brasília.: Green Fiscal Policy Workshop Cambridge Econometrics, 2015.

SABAINI, Juan C. Gómez; MORÁN, Dalmiro. Política Tributaria y Protección Del Medio ambiente: Imposición sobre Vehículos en América Latina. In: CEPAL/ AECID, 2013. Série Macroeconomía Del Desarrollo, n.141, Out. 2013. Disponível em: < http://bit.ly/MtmarZ > Acesso em: nov. 2014.

SALMONS, Roger. Road transport fuel prices, demand and tax revenues: impact of fuel duty escalator and price stabiliser. London: Policy Studies Institute (PSI), Feb. 2011. Disponível em: < http://bit.ly/1DORN6o > Acesso em: nov. 2014.

SECRETARIA DE POLÍTICA ECONÔMICA. Ministério da Fazenda. Coordenação-Geral de meio ambiente e mudanças climáticas. In: Seminário de política fiscal verde, 2015, mar. 2015.

TAVORA, Fernando.L. et al.. Núcleo de Estudos e Pesquisas, CONLEG, Senado. Comentários à Lei no 13.123, de 20 de maio de 2015: Novo Marco Regulatório do Uso da Biodiversidade. Brasília: Núcleo de Estudos e Pesquisas/CONLEG/Senado, outubro/2015 (Texto para Discussão no 184). . Disponível em: < www.senado.leg.br/ estudos > Acesso em: 20 out. 2015.

TRIBUNAL DE CONTAS DO MUNICIPIO DE SÃO PAULO. Prefeitura do município de São Paulo. Relatório anual de fiscalização: exercício de 2011. São Paulo, 2011.

YOUNG, Carlos Eduardo et al. How Green is my Budget? Public Environmental Expenditures in Brazil (2002-2010). Instituto de Economia, Rio de Janeiro, Federal University of Rio de Janeiro (UFRJ/IE), p.1-27, 2012.: Disponível em: < http://bit.ly/2gOJ8f 3 > Acesso em: out. 2014. 
; QUEIROZ, Julia M.; ROCHA, Érico. R. P. Relatório de pesquisa: avaliação dos critérios de sustentabilidade dos financiamentos apoiados pelos fundos constitucionais brasileiros. In: Comisión Económica Para América Latina Y El Caribe (Cepal), 2007, Santiago. Documento de proyecto, U.N. Santiago: CEPAL 2007. p.1-65.

; SANTORO, André F. 2011. Evolução recente das despesas ambientais do

Governo Federal Brasileiro. Nota Técnica GEMA n.1. Rio de Janeiro: GEMA-IE-UFRJ, $9 \mathrm{p}$. 